\title{
CORRESPONDÊNCIA OFICIAL E LITERATURA
}

\author{
Maria José Ferreira Strogenski \\ Especialista no Ensino de Língua Portuguesa e Literatura Brasileira pelo CEFET-PR
}

RESUMO

Há muito imagina-se que a correspondência oficial é destituída de características de linguagem literária. Todavia, parece-nos quase impossível pensar em qualquer tipo de texto que não possua tais características. Se os textos históricos já estão sendo analisados sob o ponto de vista literário e se os textos e/ou correspondências oficiais são considerados documentos históricos, estes também deveriam ser analisados da mesma forma.

\section{"Senhor:}

Mesmo que o Capitão - mor dessa vossa frota e também os outros capitães escrevam a Vossa Alteza a notícia do achamento desta vossa Terra Nova que, agora, nesta navegação se achou não deixarei, também, de dar disso minha conta a Vossa Alteza, tal como eu melhor puder ainda que para bem contar e falar o saiba fazer pior que todos...

Pero Vaz de Caminha".

Acima, com certeza, está o primeiro exemplo de correspondência oficial no Brasil. Há muito que se imagina ou se pretende que a correspondência oficial seja, na sua maioria, um tipo de texto desprovido de características literárias. Porém, como não se obtiveram informações da existência de pesquisas literárias relativas a correspondências oficiais, no sentido de se esse tipo de texto apresenta ou não tais características, qualquer conclusão é suposição.

Mas que textos são esses? Como são feitos? Quais regras seguem?

De acordo com o Manual da Presidência da República, "A redação oficial deve caracterizar-se pela impessoalidade, uso do padrão culto de linguagem, clareza, concisão, formalidade e uniformidade."

Outra instrução desse Manual, que possui publicações anteriores, conforme as necessidades de alterações, diz que:

Lembre-se que o padrão culto nada tem contra a simplicidade de expressão, desde que não seja confundida com pobreza de expressão. De nenhuma forma o uso do padrão culto implica emprego de linguagem rebuscada, nem dos contorcionismos sintáticos e figuras de linguagem próprios da língua 
Interessante essa observação quanto ao uso de figuras de linguagem, pois se trata de uma caractrística da linguagem literária. Conclui-se que o autor se está referindo às metáforas, hipérboles, etc. Mas será realmente possível que, apesar desse alerta, essas figuras de linguagem não tenham sido utilizadas?

A maioria das pessoas não dispõe de talento literário para redigir as correspondências, o que não significa, porém, que características de linguagem literária não existam nesses textos.

Conforme BAKHTIN (2000), "qualquer enunciado considerado isoladamente é, claro, individual, mas cada esfera de utilização da língua elabora seus tipos relativamente estáveis de enunciados, sendo isso que denominamos gêneros do discurso".

A correspondência oficial com certeza apresenta um tipo específico de gênero do discurso, com uma linguagem própria que, apesar do que ditam as normas, não é uniforme. Isso porque os aspectos sociais, regionais e individuais da produção de correspondências são diferentes.

Para BAKHTIN (1992),

"enquanto falo, sempre levo em conta o fundo aperceptivo (sic) sobre o qual minha fala será recebida pelo destinatário: o grau de informação que ele tem da situação, seus conhecimentos especializados na área de determinada comunicação cultural, suas opiniões e suas convicções, seus preconceitos (de meu ponto de vista), suas simpatias e antipatias, etc.; pois é isso que condicionará sua compreensão responsiva de meu enunciado. Esses fatores determinarão a escolha do gênero do enunciado, a escolha dos procedimentos composicionais e, por fim, a escolha dos recursos lingüísticos, ou seja, o estilo do meu enunciado".

Ao seguirmos o raciocínio utilizado por BAKHTIN, podemos aplicá-lo, sem nenhum problema, a um texto oficial. A preocupação com o destinatário, seu perfil, profissão, posição social são quase regras de como elaborar uma boa correspondência. BAKHTIN argumenta sobre como um texto vai sendo produzido para concluir dizendo: " ... e por fim a escolha dos recursos lingüísticos, ou seja, o estilo do meu enunciado."

Os ofícios, por exemplo, são utilizados como forma de correspondência oficial já há bastante tempo e têm registros datados desde a época do império. Considerando-se que naquela época, os aspectos políticos e ideológicos, e o fato de que quem produzia a correspondência normalmente eram pessoas diferenciadas na sociedade (principalmente por serem alfabetizadas), parece lógico concluir que manifestavam de alguma forma suas opiniões, crenças, etc. Principalmente porque, ao longo de nossa história, são incontáveis os escritores 
que se tornaram funcionários públicos e o contrário.

Ao se escrever qualquer tipo de texto, o indivíduo sempre procura, mesmo que muitas vezes sem sucesso, atrair a atenção do leitor, seduzi-lo. No caso das correspondências oficiais não é diferente.

O Manual da Presidência da República, estabelece que um ofício deverá ser escrito em três partes. Um parágrafo de início, um parágrafo de desenvolvimento, ou o do assunto propriamente dito, e um parágrafo de encerramento. Os livros de redação de correspondência também orientam que os parágrafos iniciais e finais deverão evitar os chavões e os vícios de linguagem típicos da introdução e da despedida deste tipo de texto.

Ora, o primeiro parágrafo deverá atrair o leitor, convidá-lo a ler com atenção o texto que segue. Em muitas correspondências é possível verificar a importância do destinatário através desse parágrafo. Isso em razão da linguagem escolhida e dos adjetivos utilizados. No parágrafo de desenvolvimento do assunto, a explanação deverá ser concisa, clara, para que, em poucas linhas, o interlocutor entenda a mensagem.

Uma das normas antigas quanto ao ofício definia que um ofício deveria tratar de um só assunto. Caso um ofício fosse muito longo e utilizasse, por exemplo, duas páginas, nas primeiras só deveriam ser escritas 13 linhas. O restante do assunto deveria ir para a segunda. Isso significa, escrever, seduzir, muitas vezes convencer o interlocutor, num texto restrito e com regras bastante claras.

Entretanto, são comuns os ofícios que ao invés de concisos se estendam por mais de uma página, com figuras e usos de linguagem que estão longe de ser impessoais, ou desapaixonados.

FRIEDRICH (1991) ao falar da lírica moderna, reflete sobre a poesia de Baudelaire, dizendo o seguinte: "...Mas mostra muito de seu anseio de segurança através da forma, do "salva - vidas das formas"...". Em outro trecho, diz: "É de todo evidente que as leis métricas não são tiranias inventadas arbitrariamente. São regras exigidas pelo próprio organismo espiritual. Jamais impediram à originalidade de realizar-se."

Ao tentar convencer o interlocutor de alguma coisa, o que muitas vezes é comum, uma vez que os ofícios são recheados de posturas ideológicas, o redator fará uso de qualquer meio, de língua e/ou estilo. Retornando a FRIEDRICH: "Este não mais participa em sua criação como pessoa particular, porém como inteligência que poetiza, como operador da língua, como artista que experimenta os atos da transformação de sua fantasia imperiosa ou de seu modo irreal de ver num assunto qualquer, pobre de significado em si mesmo.".

Mesmo que não se trate de poesia, o que não impede que seja poético, o texto da correspondência também estará, muitas vezes, tratando de assunto "pobre de significado", mas rico em intenção. Para FRIEDRICH, isto é assunto da poética. 
BENJAMIM (1975), ao discorrer sobre o narrador, se utilizará de uma representação similar: "A narrativa, tal como se desenvolve durante muito tempo no círculo dos ofícios mais diversos - do agrícola, do marítimo e, depois, do urbano -, é, por assim dizer, uma forma artesanal da comunicação..." ou ainda "...assim a narrativa revelará sempre a marca do narrador, assim como a mão do artista é percebida, por exemplo, na obra de cerâmica. Trata-se da inclinação dos narradores de iniciarem sua estória com uma apresentação das circunstâncias nas quais foram informados daquilo que em seguida passam a contar." p. 68

Na elaboração de qualquer texto podemos afirmar que o autor é um artista que utiliza a língua como objeto. Não é diferente no caso do texto de correspondência. Muitas vezes é possível se identificar um autor de um ofício lendo seus diversos textos.

É comum, atualmente, a utilização de citações, estórias, fatos que dêem mais ênfase ao que se pretende tratar. Como essas citações são selecionadas? O que impulsiona o redator a escolhê-las?

No caso das correspondências, torna-se imprescindível fazer uma análise histórica e ideológica para que se conclua, inclusive, quais são as convicções de um parlamentar por exemplo. Uma correspondência faz parte, muitas vezes, de um processo. Alguém que ocupa uma função pública ou parlamentar já o faz a partir de crenças e princípios político-partidários. Geralmente está envolvido em um momento social e histórico, a favor ou contra uma maioria. Imerso na política do cotidiano. Se essa função exige comunicação escrita, o tom de cada correspondência se alterará, conforme o destinatário e o que se sabe dele.

Em se tratando dos parlamentares, o início da correspondência dependerá totalmente disto. A grande maioria delas então passará a ser uma forma de transmitir uma impressão. Freqüentemente, o ofício assumirá um aspecto quase de pronunciamento político. É nesses casos que, acredita-se, aparecem aspectos de texto literário.

Em um de seus ensaios, ANTONIO CÂNDIDO (1979), ao escrever sobre literatura e desenvolvimento diz: "As áreas subdesenvolvidas e os problemas do subdesenvolvimento (ou atraso) invadem o campo da consciência e da sensibilidade do escritor, propondo sugestões, erigindo-se em assunto que é impossível evitar, tornando-se estímulos positivos ou negativos da criação."Esse trecho parece definir bem a importância do contexto social e histórico para a criação de um texto, qualquer que seja.

Aliás, CÂNDIDO (1990), na obra Interpretação, dirá ainda:

"Nas ciências humanas a forma do discurso é já um efeito de estilo, interferindo na constituição do objeto de conhecimento. Será tanto maior essa interferência quanto mais o trabalho teórico tem por alvo reduzir a modelos a experiência histórica de época ou de períodos. Assim o historiador, por mais que tenha em vista a determinação de estrutura econômica e culturais, não poderá abandonar de todo a ordem dos acontecimentos a que, em última instância, se reportam os modelos que pode construir. Os estudos dos efeitos 
de estilo tornam-se parte essencial da epistemologia da História."

Ao se analisar em Literatura os estilos, ou um contexto histórico, é natural que se busque o período histórico em que uma correspondência foi escrita. Ao se imaginar um parlamentar engajado em um partido político, defensor de determinadas idéias, supõe-se que essas idéias interferirão em sua escrita. Se esse mesmo parlamentar, por exemplo, viveu em pleno período romântico, no qual as idéias abolicionistas estavam com todo vigor, quando os escritores e oradores defendiam acirradamente a abolição e a independência, ele possivelmente poderia ter simpatizado e se colocado ao lado desses pensadores. Ele compartilharia suas opiniões, e as assimilaria mesmo sem consciência disso. Conseqüentemente passaria a defendê-las em sua vida pública e na forma como redigiu suas correspondências.

Se, por outro lado, quem redigiu um ofício foi alguém que, no final do século passado trabalhou como funcionário público em qualquer órgão governamental e, sabendo-se que muitos desses funcionários eram pessoas privilegiadas socialmente por seu nível de escolaridade e de convívio social, muitos inclusive escritores, como já foi dito anteriormente, como não imaginar que, na qualidade de leitores de obras literárias, não fossem produtores de textos com marcas dessas obras?

O estudo da História tem evoluído e suas abordagens e análises de documentos têm-se modificado. Conforme HUNT (1992) :

"De fato, o único traço verdadeiramente distintivo da nova abordagem cultural da história é a abrangente influência da crítica literária recente, que tem ensinado aos historiadores a reconhecer o papel ativo da linguagem, dos textos e das estruturas narrativas na criação e descrição da realidade histórica".

Essa influência terá ocorrido somente nos documentos históricos? Documentos esses que primavam pela intenção de impessoalidade, imparcialidade? Muito provavelmente não, os textos oficiais e/ou as correspondências oficiais certamente sofreram influências da linguagem literária ou apresentaram algumas de suas características.

Citando Peter Gay (1990) em O estilo na história, "a história é uma arte durante boa parte do tempo, e é uma arte por ser um ramo da literatura". Sendo os documentos oficiais, inclusive as correspondências, considerados documentos históricos, podemos, por analogia, concluir que de alguma forma são documentos literários.

Ao se refletir quanto a algumas dessas questões, isto é, características literárias, ou o uso de linguagem literária nos textos oficiais, tal reflexão nos aponta para a necessidade de uma pesquisa que consiga fazer considerações sobre essas influências na construção de um texto, mesmo sendo ele uma correspondência oficial.

Em um trabalho mais aprofundado, o primeiro passo seria definir se existem 
características da linguagem literária e a função das referências e/ou citações literárias presentes nos textos oficiais, para se verificar se estas foram utilizadas dentro do contexto do texto ou se só serviram como ilustração. Em seguida, fazer investigações quanto ao estilo: se jornalístico, jurídico, professoral, poético, informativo, etc. para finalmente avaliar a ocorrência ou não de características de linguagem literária.

É possível fazermos algumas considerações que nos levam a crer, ainda que sem uma pesquisa científica a respeito, que existem de fato muitas características não só de linguagem literária.

Porém, o mais importante é modificar a forma como os textos oficiais sãos vistos. O fato de se aceitar que um texto oficial pode apresentar características literárias modifica não só a forma como esses textos vêm sendo trabalhados mas a sua utilização como instrumento de compreensão de períodos históricos, sociais e literários.

A História, ao modificar a forma como vem analisando os textos históricos, nos revela um outro lado da história, revela-nos um pouco do próprio historiador. Um texto oficial poderá nos trazer também um pouco mais do que as informações que contém, e nos apresentar além dos novos aspectos a respeito do autor, novos aspectos a respeito de seu contexto.

Portanto, uma análise literária de um texto oficial poderá contribuir muito não só com a Literatura, mas com a História.

\section{REFERÊNCIAS BIBLIOGRÁFICAS}

AGUIAR, Flávio; MEIHY, José Carlos Sebe Bom \& VASCONCELOS, Sandra Guardini T. (Orgs.). Gêneros de Fronteira. Cruzamentos entre o histórico e o literário. São Paulo : Xamã, 1997.

BAKHTIN, Mikhail. O problema dos Gêneros do Discurso. In - Estética da Criação

Verbal. São Paulo : Martins Fontes, 2000. p.321

BENJAMIN, Walter. Magia e Técnica, arte e política. In: Os Pensadores, XLVIII, 1975.

CÂNDIDO, Antônio. Interpretação. Segundo Colóquio UERJ. Rio de Janeiro: Imago Ed., 1990. (Série Diversos).

Literatura e subdesenvolvimento. In: América Latina em sua Literatura. São Paulo 
: Perspectiva, 1979.

CHAVES, Flávio Loureiro. História e Literatura. Porto Alere : Ed. Da

Universidade/UFRGS. MEC/SESu/PROED, 988

FRIEDRICH, Hugo. Estrutura da Lírica Moderna : (da metade do século XIX a meados do século XX). $2^{\mathrm{a}}$ ed. São Paulo : Livrarias Duas Cidades Ltda., 1991.

GAY, Peter. O estilo na história.: GIBBON, RANKE, MACAULAY,

BURCKHARDT; tradução Denise Bottmann. São Paulo : Companhia das

Letras,

1990

HUNT, Lynn. A nova história cultural. Tradução Jefferson Luiz Camargo. São Paulo :

Martins Fontes, 1992. (O Homem e a História).

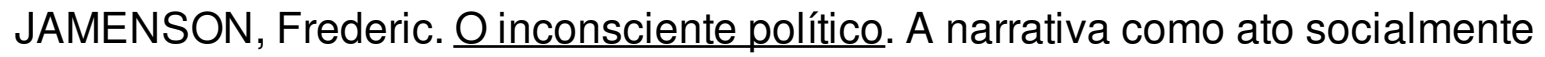
simbólico. São Paulo : Ática, 1992.

KASPARY, Adalberto J. Redação oficial : Normas e modelos. $6^{\text {a }}$ ed. Porto Alegre :

Fundação para o Desenvolvimento de Recursos Humanos, 1985.

MENDES, Gilmar Ferreira. Manual da Presidência da República. Brasília: Presidência da República, 1991.

Pero Vaz de Caminha. In CAMPEDELLI, Samira Youssef. Literatura : História \& Texto1. $2^{\mathrm{a}}$ ed. São Paulo : Editora Saraiva,1995. 